\title{
Correction to: Level of job satisfaction and associated factors among health care professionals working at University of Gondar Referral Hospital, Northwest Ethiopia: a cross-sectional study
}

\author{
Getnet Gedif ${ }^{*}$, Yetnayet Sisay ${ }^{3}$, Animut Alebel $^{2}$ and Yihalem Abebe Belay ${ }^{1}$
}

\section{Correction to: BMC Res Notes (2018) 11:824}

https://doi.org/10.1186/s13104-018-3918-0

Following publication of the original article [1], the authors reported that one of the authors' names was spelled incorrectly. In this Correction the incorrect and correct author name are shown. The original publication of this article has been corrected.

Originally the author name was published as:

- Genet Gedif

The correct author name is:

- Getnet Gedif

\section{Author details}

${ }^{1}$ Department of Public Health, College of Health Sciences, Debre Markos University, P.O.BOX:269, Debre Markos, Ethiopia. ${ }^{2}$ Department of Nursing, College of Health Sciences, Debre Markos University, Debre Markos, Ethiopia. ${ }^{3}$ Department of Health Education and Behavioral Science, Institute of Public Health, University of Gondar, Gondar, Ethiopia.
The original article can be found online at https://doi.org/10.1186/s1310 4-018-3918-0.

\section{Publisher's Note}

Springer Nature remains neutral with regard to jurisdictional claims in published maps and institutional affiliations.

Received: 21 November 2018 Accepted: 21 November 2018 Published online: 04 December 2018

\section{Reference}

1. Gedif G, Sisay Y, Alebel A, Belay YA. Level of job satisfaction and associated factors among health care professionals working at University of Gondar Referral Hospital, Northwest Ethiopia: a cross-sectional study. BMC Res Notes. 2018;11:824. https://doi.org/10.1186/s13104-018-3918-0.

\footnotetext{
*Correspondence: get4ged@gmail.com

${ }^{1}$ Department of Public Health, College of Health Sciences, Debre Markos University, P.O.BOX:269, Debre Markos, Ethiopia

Full list of author information is available at the end of the article
} 